\title{
Trypanosoma brucei: trypanocidal and cell swelling activities of lasalocid acid
}

\author{
Dietmar Steverding ${ }^{1} \cdot$ Adam Huczyński $^{2}$
}

Received: 26 June 2017 / Accepted: 18 September 2017 /Published online: 27 September 2017

(C) The Author(s) 2017. This article is an open access publication

\begin{abstract}
Chemotherapeutic treatment of human and animal trypanosomiasis is unsatisfactory because only a few drugs are available. As these drugs have poor efficacy and cause adverse reactions, more effective and tolerable medications are needed. As the polyether ionophore antibiotic lasalocid acid is used as medicated feed additive in cattle, the compound was tested for its trypanocidal and cytotoxic activity against bloodstream forms of Trypanosoma brucei and human myeloid HL-60 cells. The concentrations required of lasalocid acid to reduce the growth rate of trypanosomes by $50 \%$ and to kill the parasites were 1.75 and $10 \mu \mathrm{M}$, respectively. The ionophore displayed also cytotoxic activity against HL-60 cells but the human cells were about 10 to 14 times less sensitive indicating moderate selectivity. As the trypanocidal mechanism of action of polyether ionophore antibiotics is due to a sodium influxinduced cell swelling, the effect of lasalocid acid on cell volume change in bloodstream-form trypanosomes was investigated. Interestingly, lasalocid acid induced a much faster cell swelling in trypanosomes than the more trypanocidal related ionophore salinomycin. These results support further investigations of lasalocid acid and derivatives thereof as potential agents against African trypanosomiasis.
\end{abstract}

Electronic supplementary material The online version of this article (https://doi.org/10.1007/s00436-017-5624-6) contains supplementary material, which is available to authorized users.

Dietmar Steverding

dsteverding@hotmail.com

1 Bob Champion Research \& Education Building, Norwich Medical School, University of East Anglia, Norwich, UK

2 Faculty of Chemistry, Adam Mickiewicz University, Poznań, Poland
Keywords African trypanosomiasis - Trypanosoma brucei . Lasalocid acid $\cdot$ Polyether ionophores

\section{Introduction}

African trypanosomiasis is an infectious parasitic disease of humans (sleeping sickness) and livestock (nagana disease) of similar aetiology and epidemiology. The causative agents of the diseases are flagellated protozoans of the genus Trypanosoma. The parasites are transmitted by the bite of infected tsetse flies (Glossina sp.) and live and multiply in the blood and tissue fluids of their mammalian host. The distribution of trypanosomiasis in Africa corresponds to the range of tsetse flies and comprises an area of 8 million $\mathrm{km}^{2}$ between $14^{\circ} \mathrm{N}$ and $20^{\circ} \mathrm{S}$ latitude, a region known as the tsetse belt (Steverding 2017). African trypanosomiasis has severely repressed the economic and cultural development of central Africa in the past (Steverding 2008) and still continues to cause morbidity, mortality and economic deprivation in subSaharan Africa (Steverding 2017).

Only a few drugs are currently available for chemotherapy of African trypanosomiasis (Holmes et al. 2004; Steverding 2010). All these drugs have major drawbacks including poor efficacy, significant toxicity and requirement for parenteral administration, and are being increasingly subject to drug resistance (Matovu et al. 2001; Fairlamb 2003; Delespaux and de Koning 2007). Hence, effective and better tolerated chemotherapies are urgently needed for treatment of African trypanosomiasis.

Lasalocid acid (Fig. 1) is a polyether ionophore antibiotic produced by strains of the bacterium Streptomyces lasaliensis. It is used in cattle as medicated feed additive (Bovatec $®$ ) to improve feed efficiency and to increase the rate of weight gain, and to control coccidiosis caused by Eimeria bovis and 
<smiles>CC[C@H](C(=O)[C@H](C)[C@@H](O)[C@@H](C)CCc1ccc(C)c(O)c1C(=O)O)C1O[C@](CC)(C2CC[C@@](O)(CC)[C@H](C)O2)C[C@H]1C</smiles>

(CID: 5360807)

Fig. 1 Structure of lasalocid acid. The PubChem compound identifier (CID) for the compound is shown in parentheses

Eimeria zuernii (Flanders and Gillespie 2016). In addition, lasalocid acid like other polyether ionophore antibiotics is commercially used as anti-coccidial drugs for the prevention and control of Eimeria infections in poultry (Kant et al. 2013). The related compound salinomycin has been shown in clinical pilot studies to be able to eliminate cancer stem cells and to induce partial clinical regression of heavily pretreated and therapy-resistant cancers in patients demonstrating the in vivo activity of polyether ionophore antibiotics (Naujokat and Steinhart 2012). These facts in connection with previous findings that other polyether ionophore antibiotics (salinomycin and monensin) display promising trypanocidal activities (Steverding and Sexton 2013; Steverding et al. 2016) prompted us to investigate the antitrypanosomal action of lasalocid acid and to provide a proof of concept of the potential use of this compound as trypanocide.

\section{Materials and methods}

\section{Lasalocid acid}

Lasalocid acid was purified from its sodium salt that was isolated from Avatec Premix as previously described (Huczyński et al. 2013).

\section{Cell culture}

Bloodstream forms of T. brucei (clone 427-221a; Hirumi et al. 1980) and human myeloid leukaemia HL-60 cells (Collins et al. 1977) were maintained in Baltz medium (Baltz et al. 1985) supplemented with $16.7 \%$ heat-inactivated foetal bovine serum in a humidified atmosphere containing $5 \% \mathrm{CO}_{2}$ at $37^{\circ} \mathrm{C}$.

\section{In vitro toxicity assay}

Toxicity assays were carried out as previously described (Merschjohann et al. 2001) with some modifications. In brief, cells (trypanosomes and HL-60 cells) were seeded in 96 well plates in a final volume of $200 \mu \mathrm{l}$ of the Baltz medium containing various concentrations of test compounds (tenfold dilution from $100 \mu \mathrm{M}$ to $10 \mathrm{nM}$ ) and $1 \%$ DMSO. Wells just containing medium and $1 \%$ DMSO served as controls. The initial cell densities were $1 \times 10^{4} / \mathrm{ml}$ for trypanosomes and $5 \times 10^{4} / \mathrm{ml}$ for HL- 60 cells. After $24 \mathrm{~h}$ incubation, $20 \mu \mathrm{l}$ of a $0.5 \mathrm{mM}$ resazurin solution prepared in PBS was added and the cells were incubated for a further $48 \mathrm{~h}$. Thereafter, the absorbance of wells was read on a BioTek ELx808 microplate reader using a test wavelength of $570 \mathrm{~nm}$ and a reference wavelength of $630 \mathrm{~nm}$. The $50 \%$ growth inhibition $\left(\mathrm{GI}_{50}\right)$ value, i.e. the concentration of a compound necessary to reduce the growth rate of cells by $50 \%$ compared to the control was determined by linear interpolation (Huber and Koella 1993). The minimum inhibitory concentration (MIC) values, i.e. the concentration of the drug at which all trypanosomes and human cells were killed, were determined microscopically.

\section{Swelling experiment}

Cell volume can be measured by light scattering which has been used to monitor volume change in many different cell types including bacteria, mammalian cells and protozoans. For Giardia intestinalis, a flagellated protozoan parasite like T. brucei, the absorbance of cell suspensions have been shown to be similar between 450 and $550 \mathrm{~nm}$ (Park et al. 1997). Based on the available filters of the BioTek ELx808 microplate reader, we determined changes in cell volume of trypanosomes at $490 \mathrm{~nm}$ as previously described (Steverding and Sexton 2013). In brief, bloodstream forms of T. brucei were seeded at a density of $5 \times 10^{7}$ cells $/ \mathrm{ml}$ in 96 well plates in a final volume of $200 \mu \mathrm{l}$ Baltz medium containing $100 \mu \mathrm{M}$ ionophore and $1 \%$ DMSO (test) or 1\% DMSO alone (control). Additionally, some swelling experiments were performed in the presence of $6 \mathrm{mM}$ of the divalent metal-chelating agent EDTA. Absorbance of the cultures was measured every $10 \mathrm{~min}$. A decrease in absorbance corresponds to an increase in cell volume.

\section{Results and discussion}

Lasalocid acid showed a dose-dependent inhibitory effect on the growth of bloodstream forms of T. brucei with a MIC value of $10 \mu \mathrm{M}$ and a $\mathrm{GI}_{50}$ value of $1.75 \mu \mathrm{M}$ (Fig. 2). Compared with salinomycin, lasalocid acid was 7.6 and 10 times less trypanocidal (MIC and $\mathrm{GI}_{50}$ values for salinomycin were determined to be 1 and $0.23 \mu \mathrm{M}$, respectively (Fig. 2)). On the other hand, lasalocid acid was less cytotoxic towards HL-60 cells than salinomycin, the corresponding MIC and $\mathrm{GI}_{50}$ values being 100 and $24.7 \mu \mathrm{M}$ for lasalocid acid and 1 and $0.32 \mu \mathrm{M}$ for salinomyicn, respectively (Fig. 2). Thus, while salinomycin showed no selectivity (cytotoxic to 


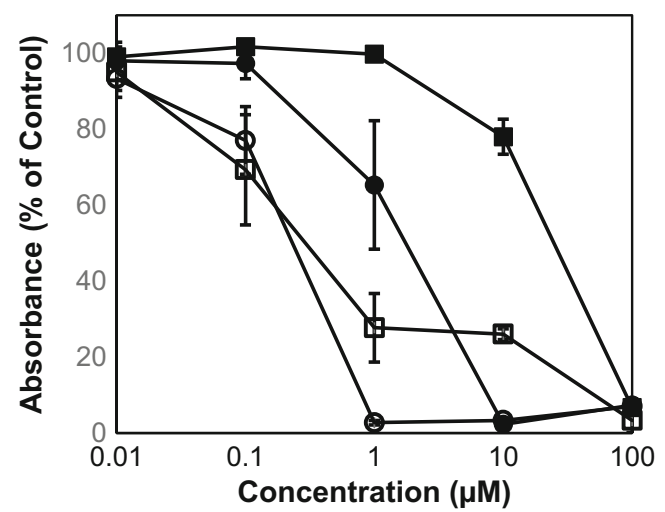

Fig. 2 Effect of lasalocid acid and salinomycin on the growth of bloodstream forms of T. brucei and human myeloid leukaemia HL-60 cell. Trypanosomes (circles) and HL-60 cells (squares) were incubated with varying concentration of lasalocid acid (closed symbols) or salinomycin (open symbols). After $72 \mathrm{~h}$ of culture, cell viability and proliferation were determined with the colorimetric dye resazurin. The experiment was repeated three times and mean values $\pm \mathrm{SD}$ of three experiments are shown

trypanocidal activity ratio) with $\mathrm{MIC}$ and $\mathrm{GI}_{50}$ ratios of 1 and 1.4 , lasalocid acid exhibited moderated selectivity with indices of $\geq 10$. The unfavourable selectivity of salinomycin can be attributed to its high cytotoxicity towards HL-60 cells, with our determined $\mathrm{GI}_{50}$ value of $0.32 \mu \mathrm{M}$ being in good agreement with previously reported values of $0.29-0.44 \mu \mathrm{M}$ (Huczyński et al. 2012, 2015; Steverding and Sexton 2013; Antoszczak et al. 2014; Steverding et al. 2016).

The biological activity of polyether ionophore antibiotics is due to initiation of an increase in the intracellular concentration of $\mathrm{Na}^{+}$cations by their ability to transport these ions across biological membranes (Pressman et al. 1980). In cancer cells, this influx of $\mathrm{Na}^{+}$cations seems to be responsible for the induction of apoptosis (Huczyński 2012) while in bloodstream-form trypanosomes, it leads to swelling of the cell by subsequent entry of water (Steverding and Sexton 2013). In addition, the rate of swelling in trypanosomes seems to be depending on the trypanocidal activity of the ionophore: the higher the trypanocidal activity, the faster the swelling (Steverding et al. 2016). Given that lasalocid acid is less trypanocidal than salinomycin, it was interesting to test whether lasalocid acid would cause a slower swelling rate compared to salinomycin. To be able to record measurable changes in absorbance, a high cell density $\left(5 \times 10^{7}\right.$ cells $\left./ \mathrm{ml}\right)$ and a high ionophore concentration $(100 \mu \mathrm{M})$ are required (Steverding et al. 2016). Surprisingly, trypanosomes incubated with lasalocid acid swelled much faster than parasites treated with salinomycin (Fig. 3a). Already, after 20 min incubation, no further swelling was recorded indicating that the endpoint of the swelling process was already reached by which the trypanosomes started to die. In contrast, trypanosomes exposed to salinomycin continued to swell until the end of the experiment and started to die after 50 min of incubation. An
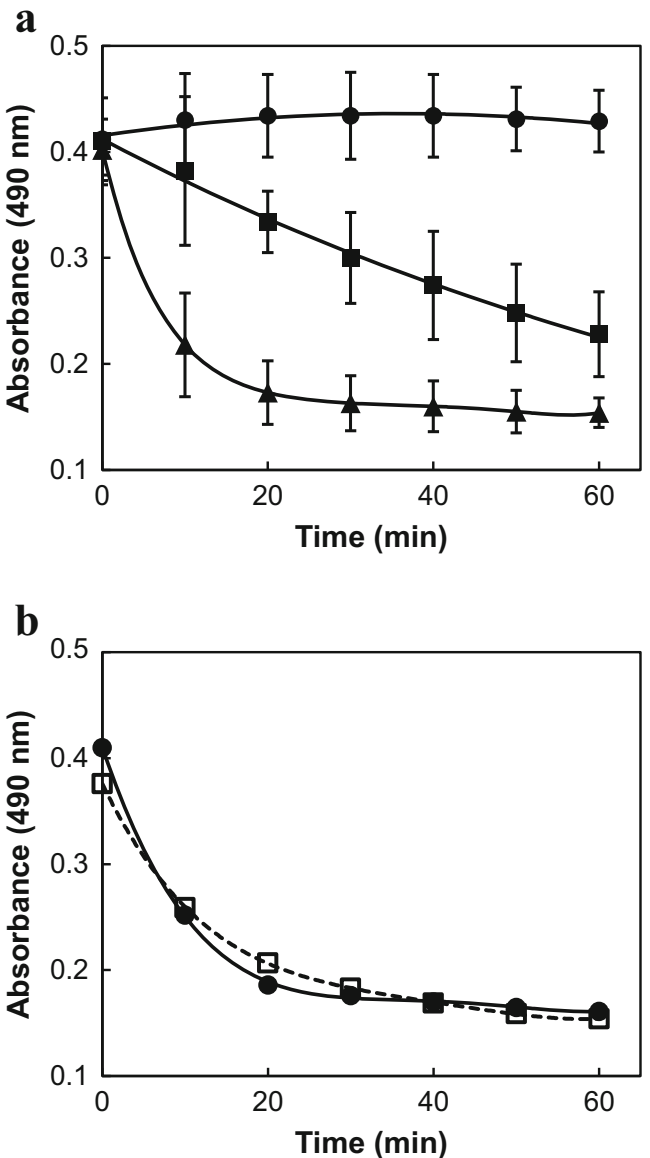

Fig. 3 Effect of polyether ionophore antibiotics on the cell volume of bloodstream forms of $T$. brucei. a Trypanosomes $\left(5 \times 10^{7} \mathrm{cell} / \mathrm{ml}\right)$ were incubated with $100 \mu \mathrm{M}$ lasalocid acid (triangles) or salinomycin (squares) in Baltz medium in the presence of $1 \%$ DMSO. Controls (circles) were incubated with $1 \%$ DMSO. Every $10 \mathrm{~min}$, the absorbance at $490 \mathrm{~nm}$ was measured. Mean values $\pm \mathrm{SD}$ of three experiments are shown. Except for the time point $0 \mathrm{~min}$ at all other time points, the absorbance values were statistically significantly different from each other (One-way ANOVA test, $p<0.01)$. b Trypanosomes $\left(5 \times 10^{7} \mathrm{cell} / \mathrm{ml}\right)$ were incubated with $100 \mu \mathrm{M}$ lasalocid acid in the absence (closed circles, solid line) or presence of 6 mM EDTA (open squares, dashed line) in Baltz medium containing $1 \%$ DMSO. Every $10 \mathrm{~min}$, the absorbance at $490 \mathrm{~nm}$ was measured. Mean values of three experiments are shown. For clarity, the standard deviations were omitted. The standard deviations ranged between $17.5-25.1 \%$ of the mean values. At each time point, the data points of the two curves were statistically not significantly different $(p=0.465-0.977$, Student's $t$ test)

explanation for the fast swelling activity of lasalocid acid may be the ability of the compound to transport $\mathrm{Ca}^{2+}$ cations across membranes that other polyether ionophore antibiotics lack (Pressman et al. 1980). In particular, the large $\mathrm{Ca}^{2+}$ concentration gradient of 20,000 (extracellular $\sim 2 \mathrm{mM}$, intracellular $\sim 100 \mathrm{nM}$; Ruben et al. 1991) would be more than sufficient to induce an ionophore-driven influx of $\mathrm{Ca}^{2+}$-ions that could cause a rapid swelling of trypanosomes. For comparison, the $\mathrm{Na}^{+}$concentration gradient is just about 10 (extracellular $144 \mathrm{mM}$, intracellular $13.7 \mathrm{mM}$; Nolan and Voorheis 2000). In order to test whether the $\mathrm{Ca}^{2+}$ transport activity of 
lasalocid acid is indeed, the reason for the observed prompt swelling of trypanosomes, a swelling experiment was carried out in the presence of $6 \mathrm{mM}$ of EDTA. This chelating agent has a much higher binding affinity for $\mathrm{Ca}^{2+}$-ions than lasalocid acid $\left(K_{\mathrm{S}}\right.$ values for the $\mathrm{Ca}^{2+}$-complexes of EDTA and lasalocid acid are $10^{7.9}$ (estimated for $\mathrm{pH} 7.5$ ) and $10^{2.57}$ (in methanol; Degani and Friedman 1974), respectively). As EDTA binds $\mathrm{Mg}^{2+}$ cations as well and as the combined concentration of $\mathrm{Ca}^{2+}$ and $\mathrm{Mg}^{2+}$ in the Baltz medium is approximately $3 \mathrm{mM}$, the employed concentration of the chelating agent of $6 \mathrm{mM}$ was determined to be sufficient to reduce the extracellular $\mathrm{Ca}^{2+}$ concentration below $10 \mathrm{nM}$, and thus significantly below the intracellular $\mathrm{Ca}^{2+}$ concentration of bloodstream forms of $T$. brucei. Under these conditions, any ionophore-driven $\mathrm{Ca}^{2+}$-transport would be in the efflux direction. However, no difference in the swelling rate of the parasites upon addition of lasalocid acid in the presence or absence of 6 mM EDTA was observed (Fig. 3b). Hence, any $\mathrm{Ca}^{2+}$ transport across the plasma membrane seems not to play any role in the lasalocid acid-induced swelling of bloodstream forms of T. brucei, and that the observed fast swelling is solely due to the influx of $\mathrm{Na}^{+}$cations. The reason why lasalocid acid and salinomycin differ in their swelling rates and trypanocidal activities may be just due to their affinity for $\mathrm{Na}^{+}$. While the lower $K_{\mathrm{S}}$ value of lasalocid acid for $\mathrm{Na}^{+}$cations $\left(10^{2.57}\right.$; Degani and Friedman 1974) favours an easier transport of the ion across membranes, the higher $K_{\mathrm{S}}$ value of salinomycin for $\mathrm{Na}^{+}$cations $\left(10^{3.31}\right.$; Pressman et al. 1980) facilitates a higher trypanocidal activity.

As chemical modification can increase the trypanocidal activity of polyether ionophore antibiotics (Steverding et al. 2016), we also studied the antitrypanosomal effect of seven Mannich base derivatives of lasalocid acid. The synthesis of the Mannich base derivatives tested is described elsewhere (Huczyński et al. 2013). However, none of the derivatives displayed better trypanocidal activity and selectivity than the parent compound lasalocid acid (Supplementary Table S1). This observation indicates that modification of the carboxyl group of lasalocid acid by Mannich base alkyl/aryl substituents is not the right approach to improve the trypanocidal activity of the ionophore. Perhaps, other modifications of the carboxyl group like esterification or amidation could afford derivatives of lasalocid acid with enhanced antitrypanosomal activity as has recently been shown for salinomycin (Steverding et al. 2016).

This study confirms previous findings that polyether ionophore antibiotics are promising antitrypanosomal agents (Steverding and Sexton 2013, Steverding et al. 2016). Although lasalocid acid, studied here, was found to be less trypanocidal than salinomycin, it had a better selectivity and induced faster swelling than other ionophores. Lasalocid acid may be directly applicable for treatment of nagana disease particularly as the ionophore is used in cattle as medicated feed additive (Bovatec $®)$. As no published data are available, it remains to be shown whether lasalocid acid supplementation can generate high enough plasma levels of the ionophore within its effective concentration range in cattle. However, when chickens were fed with $75 \mathrm{mg}$ sodium lasalocid per kilogram of feed for 1 week, the mean concentration of the antibiotic in serum was $1.36 \mu \mathrm{g} / \mathrm{ml}(=2.3 \mu \mathrm{M})$ (Stipkovits and Juhász 1987) which is above the $\mathrm{GI}_{50}$ value of $1.75 \mu \mathrm{M}$ for the trypanocidal activity of the ionophore (see above). Even if lasalocid acid as feed additive does not provide high enough plasma levels in cattle to affect substantially trypanosomes, the use of the ionophore in food could have a positive impact on the efficacy of the drugs currently employed to treat nagana disease. On the other hand, higher blood levels of lasalocid acid can be achieved by intravenous administration. For instance, intravenous injection of $5 \mathrm{mg}$ of sodium lasalocid per kilogram body weight in a dog resulted in blood levels of the ionophore of $>7.3 \mu \mathrm{g} / \mathrm{ml}(>12 \mu \mathrm{M})$ for the following $30 \mathrm{~min}$ (Brooks et al. 1975), a concentration that killed trypanosomes in our in vitro assay ( $\mathrm{MIC}=10 \mu \mathrm{M}$, see above). In addition, at normal dosage, lasalocid acid is of low toxicity and usually causes no adverse side effects in cattle. Only in cases of overdosage, cattle show signs of acute intoxication which include anorexia, dyspnoea, tachycardia, ataxia and diarrhoea. Taken together, this information warrants investigations into the in vivo trypanocidal efficacy of lasalocid acid.

Acknowledgements We would like to thank Dr. Hollian Richardson for critical reading of the manuscript.

\section{Compliance with ethical standards}

Conflict of interest The authors declare that they have no conflict of interest.

Open Access This article is distributed under the terms of the Creative Commons Attribution 4.0 International License (http:// creativecommons.org/licenses/by/4.0/), which permits unrestricted use, distribution, and reproduction in any medium, provided you give appropriate credit to the original author(s) and the source, provide a link to the Creative Commons license, and indicate if changes were made.

\section{References}

Antoszczak M, Maj E, Napiórkowska A, Stefańska J, AugustynowiczKopeć E, Wietrzyk J, Janczak J, Brzezinski B, Huczyński A (2014) Synthesis, anticancer and antibacterial activity of salinomycin $\mathrm{N}$ benzyl amides. Molecules 19:19435-19459

Baltz T, Baltz D, Giroud C, Crockett L (1985) Cultivation in a semidefined medium of animal infective forms of Trypanosoma brucei, T. equiperdum, T. evansi, T. rhodesiense and T. gambiense. EMBO J 4:1273-1277

Brooks MA, D'Arconte L, de Silva JAF, Chen G, Crowley C (1975) Spectrofluorometric determination of the antibiotic lasalocid in blood. J Pharm Sci 64:1874-1876 
Collins SJ, Gallo RC, Gallagher RE (1977) Continuous growth and differentiation of human myeloid leukaemic cells in suspension culture. Nature 270:347-349

Degani H, Friedman HL (1974) Ion binding by X-537A. Formulas, formation constants, and spectra of complexes. Biochemistry 12:50225032

Delespaux V, de Koning HP (2007) Drugs and drug resistance in African trypanosomiasis. Drug Resist Updat 10:30-50

Fairlamb AH (2003) Chemotherapy of human African trypanosomiasis: current and future prospects. Trends Parasitol 19:488-494

Flanders FB, Gillespie JR (2016) Modern livestock and poultry production, 9th edn. Cengage Learning, Boston

Hirumi H, Hirumi K, Doyle JJ, Cross GAM (1980) In vitro cloning of animal-infective bloodstream forms of Trypanosoma brucei. Parasitology 80:371-382

Holmes PH, Eisler MC, Geerts S (2004) Current chemotherapy of animal trypanosomiasis. In: Maudlin I, Holmes PH, Miles MA (eds) The Trypanosomiases. CABI Publishing, Wallingford, pp 431-444

Huber W, Koella JC (1993) A comparison of three methods of estimating $\mathrm{EC}_{50}$ in studies of drug resistance of malaria parasites. Acta Trop 55: 257-261

Huczyński A (2012) Polyether ionophores-promising bioactive molecules for cancer therapy. Bioorg Med Chem Lett 22:7002-7010

Huczyński A, Antoszczak M, Kleczewska N, Lewandowska M, Maj E, Stefańska J, Wietrzyk J, Janczak J, Celewicz L (2015) Synthesis and biological activity of salinomycin conjugates with floxuridine. Eur J Med Chem 93:33-41

Huczyński A, Janczak J, Antoszczak M, Wietrzyk J, Maj E, Brzezinski B (2012) Antiproliferative activity of salinomycin and its derivatives. Bioorg Med Chem Lett 22:7146-7150

Huczyński A, Rutkowski J, Borowicz I, Wietrzyk J, Maj E, Brzezinski B (2013) One-pot synthesis and cytotoxitiy studies of new Mannich base derivatives of polyether antibiotic - lasalocid acid. Bioorg Med Chem Lett 23:5053-5056

Kant V, Singh P, Verma PK, Bais I, Parmer MS, Gopal A, Gupta V (2013) Anticoccidial drugs used in the poultry: an overview. Sci Int (Lahore) 1:261-265
Matovu E, Seebeck T, Enyaru JC, Kaminsky R (2001) Drug resistance in Trypanosoma brucei spp., the causative agents of sleeping sickness in man and nagana in cattle. Microbes Infect 3:763-770

Merschjohann K, Sporer F, Steverding D, Wink M (2001) In vitro effect of alkaloids on bloodstream forms of Trypanosoma brucei and T. congolense. Planta Med 67:623-627

Naujokat C, Steinhart R (2012) Salinomycin as a drug for targeting human cancer stem cells. J Biomed Biotechnol 2012:950658

Nolan DP, Voorheis HP (2000) Factors that determine the plasmamembrane potential in bloodstream forms of Trypanosoma brucei. Eur J Biochem 267:4615-4623

Park J-H, Schofield PJ, Edwards MR (1997) Giardia intestinalis: volume recovery in response to cell swelling. Exp Parasitol 86:19-28

Pressman BC, Painter G, Fahim M (1980) Molecular and biological properties of ionophores. In: Martell AE (ed) Inorganic Chemistry in Biology and Medicine, ACS Symposium Series 140. American Chemical Society, Washington, pp 3-22

Ruben L, Hutchinson A, Moehlman J (1991) Calcium homeostasis in Trypanosoma brucei. Identification of a $\mathrm{pH}$-sensitive non-mitochondrial calcium pool. J Biol Chem 266:24351-24358

Steverding D (2008) The history of African trypanosomiasis. Parasit Vectors $1: 3$

Steverding D (2010) The development of drugs for treatment of sleeping sickness: a historical review. Parasit Vectors 3:15

Steverding D (2017) Sleeping sickness and nagana disease caused by Trypanosoma brucei. In: Marcondes CB (ed) Arthropod Borne Diseases. Springer International Publishing, Cham, pp 277-297

Steverding D, Antoszczak M, Huczyńsky A (2016) In vitro activity of salinomycin and monensin derivatives against Trypanosoma brucei. Parasit Vectors 9:409

Steverding D, Sexton DW (2013) Trypanocidal activity of salinomycin is due to sodium influx followed by cell swelling. Parasit Vectors 6:78

Stipkovits L, Juhász S (1987) Assay of lasalocid and monensin residues in chicken lung and serum samples of small quantity. Acta Vet Hung $35: 237-244$ 